\title{
Repeated simple sedimentation technique and prevalence of bovine schistosomosis in selected sites of Bahir Dar woreda
}

\author{
Almaz Habtamu $u^{1}$ and Solomon Wolde Mariam ${ }^{2}$ \\ ${ }^{1}$ Bahir Dar Regional Veterinary Laboratory, P.O.Box 70, Fax 058-22632263, Bahir Dar, Ethiopia \\ ${ }^{2}$ Agricultural Bureau of Amhara National Regional State P. O. Box 447, Bahir Dar
}

\begin{abstract}
The study was conducted from April 2008 to February 2009 at Bahir Dar Woreda adjoining Upper Blue Nile "Abay" river basin, northwest Ethiopia with the aim of estimating the benefit from repeated examination of faecal samples in diagnosis of bovine Schistosomosis and determining the prevalence of the disease in naturally infected cattle. Two hundred and twenty nine cattle (112 local and 117cross) were used from the population as study animals. Out of 687 faecal samples (229 cattle x 3 consecutive days) examined, 256 samples were found positive for Schistosoma bovis giving an overall prevalence of $37.3 \%$. Sampling of each animal was made for three consecutive days and schistosomosis prevalence was determined for each sample day i.e. for day1, day2 and day3. There was a significant difference $(p<0.05)$ in the prevalence of schistosomosis of cattle between day1 and day3. The prevalence of the disease in both breeds increases as sample day increases. However, in cross breed cattle the prevalence of schistosomosis was significantly $(p<0.05)$ higher than local breeds. Statistical analyses of result revealed that there were significant differences in infection between age groups $(\mathrm{P}<0.05)$. There was no significance difference $(\mathrm{P}>0.05)$ in the prevalence of Schistosoma infection between the two sex groups. This work demonstrates that the sensitivity of sedimentation techniques in detection of Schistosoma eggs of cattle increases by repeated faecal examinations. As useful method, repeated faecal examinations should be applied by veterinarians for diagnosis of schistosomosis in endemic areas of the country.
\end{abstract}

Keywords: Examinations, prevalence, repeated sample, schistosomosis, sedimentation.

\section{Introduction}

Schistosomosis is an infection which occurs due to trematodes of the genus Schistosoma. The disease is characterized by its chronic nature and affects the productivity and reproduction performances; and predisposes animals to other diseases (Dargie, 1980; McCauley et al., 1983, 1984). Schistosomosis is 
endemic in the tropical and subtropical countries of Africa, Asia and southern Europe (Lawerence, 1971; Fraser et al., 1991).

Schistosoma bovis has a localized distribution, which is found commonly in northern, eastern, southwestern and central parts of Ethiopia. Its prevalence has been reported by a number of authors; $12.3-29 \%$ in Bahir Dar (Solomon, 1985; Aemro, 1993; Hailu, 1999; Yalelet, 2004; Almaz, 2007) and 28\% in Kemissie (Ameni et al., 2001) by coproscopic examination. Abattoir surveys conducted in different periods in Bahir Dar revealed prevalence at a rate of 48\% (Hailu, 1999); 30.3\% (Yalelet, 2004) and 28.14\% (Almaz, 2007).

Diagnosis is based primarily on the clinicopathological picture, seasonal occurrence, and previous history of schistosomosis in the area or the identification of snail habitats with a history of access to natural water bodies. Postmortem examination, haematological tests and examination of faeces for Schistosoma eggs are useful (Urquhart et al., 1997).

Proper diagnosis of the disease is important in prescribing effective drugs. It assists any control programs directed to schistosomosis. Ineffectiveness of some treatments follows partly from poor diagnosis, leading to the application of inappropriate treatments.

The clinical signs alone will not suffice to arrive at a definite diagnosis, but they should indicate the necessity of faeces examination, which will reveal the eggs of the parasites mixed with blood and mucus (Soulsby, 1982). However, simple faecal examination in detection of Schistosoma eggs in chronic form has not achieved a level of reliability for use in animals. Therefore, the most direct and reliable technique for the diagnosis of schistosomosis is postmortem examination.

The aim of the study is, therefore, to estimate the benefit from repeated examination of faecal samples in diagnosing bovine Schistosomosis and determining the prevalence of the disease in naturally infected cattle at Bahir Dar, northwestern Ethiopia.

\section{Materials and methods}

\section{Study area}

The study was conducted from April 2008 to February 2009 at Bahir Dar Woreda adjoining Upper Blue Nile "Abay" river basin, northwest Ethiopia. Bahir Dar is bordered with Lake Tana and having an altitude ranging from 
1600-1800 m.a.s.l and has a warm humid climate with an average annual rainfall of $700 \mathrm{~mm}$. The annual temperature of the area ranges from $12.4^{\circ}$ $-27^{\circ} \mathrm{C}$. The area has poor drainage and there is annual over flooding during the rainy seasons leaving pockets of water bodies for long period during the dry season. Both traditional and modern (semi intensive) farming are practiced in the study area (CSA, 2008).

\section{Study animals}

The sampling units for the study were phenotypically grouped local and cross breed of cattle managed under the traditional husbandry system. All study animals were often kept out-doors and grazed all day near the vicinity of the Lake Tana and the Blue Nile river and its tributaries (Andasa and Tikurit). These areas are used as communal grazing lands and water points for the study animals.

Attempts were made to include all age (young $=<2 \mathrm{yrs}$, adult $=2-5 \mathrm{yrs}$ and old $=>$ $5 \mathrm{yrs}$ ) and sex (male and female) groups of cattle in the study. However, farmer practices of the area prove that more female animals are kept than male ones. Owing to this reason, we were unable to select equal numbers of study animals on sex basis. The age of each animal was estimated using the dentition pattern of the animal as described in Williamson and Payne (1959). A total of 229 animals were used from the population as study animals. Sampling of each animal was made for three consecutive days and schistosomosis prevalence was determined for each sample day i.e. for day1, day2 and day3. The collection time of faeces was maintained uniformly.

\section{Study design}

The study was a repeated cross-sectional type of study estimating the advantage of repeated examination of faecal samples in diagnosis of bovine schistosomosis in selected sites of Bahir Dar woreda. The desired sample size for the study was calculated using the formula given by Thrusfield (1995) with $95 \%$ confidence interval, $5 \%$ absolute precision and we considered $18.2 \%$ average prevalence of cattle schistosomosis for the area. Accordingly, 229 animals were selected purposively from schistosomosis risk areas of the woreda. 


\section{Study methodology}

\section{Coprological examination}

Faecal samples were collected from the study animals directly from rectum for three consecutive days. All faecal samples were stored in clean universal bottle containing $10 \%$ formalin and labelled separately until examination. We used a modified simple sedimentation technique recommended by Antonia et al. (2002). Each sample was examined repeatedly more than four times.

\section{Statistical analysis}

Using SPSS program, data were summarized and analyzed. Chi square (x2) test was used to determine the variation in the prevalence of Schistosoma infection between ages, sexes and breeds in three consecutive days. A 5\% significance level was used to determine whether there are significant differences between measured parameters.

\section{Result}

\section{Prevalence of Schistosoma infection}

Sample days

Out of 687 faecal samples (229 cattle x 3 consecutive days) examined, 256 samples were found positive for Schistosoma bovis giving an overall prevalence of $37.3 \%$. Different results in the prevalence of the disease were encountered during examination of faeces collected from the same animals in three consecutive sample days. There was a significant difference $(p<0.05)$ in the prevalence of schistosomosis of cattle between day1 and day3 (Figure 1). The result showed that there was no statistically significant difference $(\mathrm{P}>0.05)$ in prevalence between day 2 and day3.

Breed, age and sex

Attempts were made to evaluate the effect of age and breed on the overall prevalence of schistosomosis during examination of faecal samples repeatedly. We observed that the prevalence of the disease in both breeds increases as sample day increases. However, in cross breed cattle the prevalence of schistosomosis was significantly $(\mathrm{p}<0.05)$ higher than local breeds (Table 1$)$. Statistical analyses of result revealed that there were significant differences in infection between age groups $(\mathrm{P}<0.05)$ on the basis of sample days (Table 2$)$. 
Statistically, there was no significance difference $(\mathrm{P}>0.05)$ in the prevalence of Schistosoma infection between the two sex groups (Table 3).

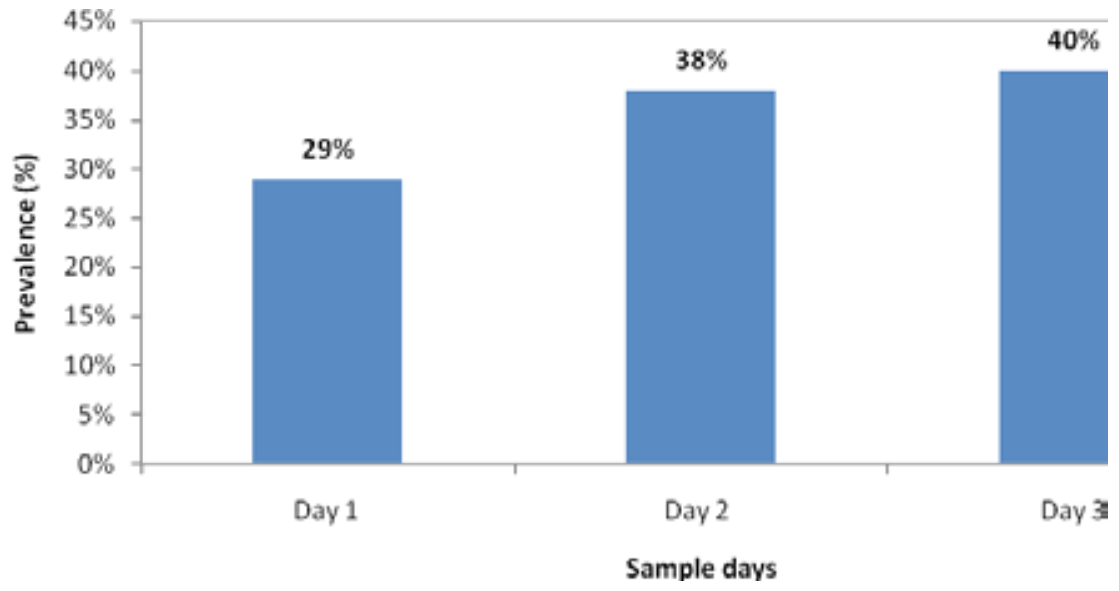

Figure 1. Prevalence of Schistosoma bovis based on sample days.

Table1. Prevalence of bovine schistosomosis based on breed type in 3 sample days.

\begin{tabular}{lccc}
\hline Breed & Day1 & Day2 & Day3 \\
\hline Cross & $39(33.3 \%)$ & $48(41.0 \%)$ & $52(44.4 \%)$ \\
Local & $28(25.0 \%)$ & $38(33.9 \%)$ & $40(35.7 \%)$ \\
$\mathrm{X}^{2}$ test & 39.41 & 14.18 & 17.33 \\
$\mathrm{df}$ & 1 & 1 & 1 \\
P- value & 0.00 & 0.00 & 0.00 \\
\hline
\end{tabular}

Table 2. Prevalence of bovine schistosomosis based on age group in 3 sample days.

\begin{tabular}{lccc}
\hline Age & Day1 & Day2 & Day3 \\
\hline Young & $26(51.0 \%)$ & $32(62.7 \%)$ & $34(66.7 \%)$ \\
Adult & $21(39.6 \%)$ & $31(58.5 \%)$ & $34(64.2 \%)$ \\
Old & $20(16.0 \%)$ & $23(18.4 \%)$ & $24(19.2 \%)$ \\
$\mathrm{X}^{2}$ test & 24.34 & 43.26 & 54.73 \\
df & 2 & 2 & 2 \\
P- value & 0.00 & 0.00 & 0.00 \\
\hline
\end{tabular}


Table 3. Prevalence of bovine schistosomosis between two sexes in 3 sample days.

\begin{tabular}{lccc}
\hline Sex & Day1 & Day2 & Day3 \\
\hline Male & $18(36.0 \%)$ & $20(40.0 \%)$ & $20(40.0 \%)$ \\
Female & $49(27.4 \%)$ & $66(36.9 \%)$ & $72(40.2 \%)$ \\
$\mathrm{X}^{2}$ test & 1.40 & 0.16 & 0.00 \\
df & 1 & 1 & 1 \\
P- value & 0.29 & 0.74 & 1.00 \\
\hline
\end{tabular}

\section{Discussion}

The result of the study has revealed relatively high prevalence of Schistosoma bovis $(37.3 \%)$ in cattle than values reported by previous attempts (12.3-29\%) (Aemro, 1993; Hailu, 1999; Yalelet, 2004; Almaz, 2007). This wide gap may be due to the fact that the previous studies were undertaken by means of single faecal sample examination which is used traditionally in the diagnosis of parasites egg. This has resulted in lower probability of detecting Schistosoma eggs in faeces. It is believed that trematodes are intermittent egg layers so that the chance of detecting eggs during single faecal sample examination may be minimal (Bushara et al., 1980.)

Prevalence according to day1 examinations were $29 \%$. Day2 examinations increased this by $9 \%$ and day3 examinations by $11 \%$. The result indicated an improvement in the detection of Schistosoma infection of cattle. Though a repeated examination of faecal samples is a time-consuming process, it is advantageous that examination of more than four slides in a sedimentation technique would most likely increase the sensitivity. Thus, repeated sampling method increases the chance of finding eggs in the faeces.

This study showed that the prevalence of the disease in both local and cross breed cattle was increased as sample day increases. Nevertheless, high value in prevalence was recorded in cross breed cattle as compare to local breeds (Table 1). The likely explanation might be local breeds were acquired a high degree of immunity as a result of repeated natural exposure. The main manifestation of immunity was suppression of worm fecundity (Bushara et al., 1980). It was also reported that local cattle that are naturally acquired infections are capable of reducing egg production. Furthermore, there is difference in natural or innate immunity between indigenous and cross breed of cattle (Fekadu, et.al., 1989).

Analysis results revealed variation in prevalence of schistosomosis of cattle was observed between age groups during sampling days (Table 2). This disparity 
may be associated with variation in establishment of acquire immunity. High prevalence of the disease was observed in young and adult cattle groups rather than in older ones. This could be attributed to the fact that calves are traditionally wined at about 1.5-2 years and then allowed to graze with adult cattle. In addition to this adult group of cattle are left to graze on the field were cercaria infection is high, furthermore in this group of animals acquired immunity is not established hence egg shed in these animals is high (Bont, 1995). While in older group of cattle due to development of acquired resistance there is decrease in egg release.

This survey reveals that there is no significant difference $(\mathrm{P}>0.05)$ in prevalence of schistosomosis on sex basis. The likely explanation may be that both sex groups grazing in similar Schistosoma contaminated pasture land and water points are highly susceptible to the risk of acquisition of the infection. Therefore, the disease appeared to be well distributed among the two sexes.

In conclusion, this study has found simple repeated faecal examinations have increased the chance of detecting Schistosoma eggs in naturally infected animals. It can be strongly suggested that single faecal examination can result in underdiagnosis of weak infection of schistosomosis. Schistosomosis is an edemic parasitic disease of cattle at Bahir Dar, Northwestern Ethiopia.

Therefore, repeated faecal examinations, as useful method, should be applied by veterinarians for the diagnosis of schistosomosis in endemic areas of the country. Cross-bred cattle, as they are highly susceptible, have to be kept indoors so as to prevent the infection. It is important that by supplying clean water to cattle, schistosomosis can further be managed. Strategic treatment interventions should be applied to prevent losses incurred by schistosomosis in the study area.

\section{References}

Aemro, T. (1993). Assessment of prevalence, economic significance and drug efficacy trial on bovine schistosomosis in Bahir Dar, Ethiopia. DVM Thesis, Faculty of Veterinary Medicine, Addis Ababa University

Almaz, H. (2007). Pathology of naturally occurring Schistosoma infection in cattle slaughtered at Bahir Dar municipal abattoir, northwest Ethiopia. MSc Thesis, Faculty of Veterinary Medicine, Addis Ababa University

Ethiop. Vet. J., 2011, 15 (1), 49-57 
Ameni, G., Krok, B. and Bogale, T. (2001). Preliminary study on the major bovine trematode infection around Kemissie, Northeastern Ethiopia and treatment trial with praziquantel. Bull. Anim. Hlth. Prod. Afr, 49, 62-67

Antónia, M., Conceição, P., Rute M. Durão, Isabel H. Costa, José M. Correia da Costa (2002). Evaluation of a simple sedimentation method (modified MacMaster) for diagnosis of bovine fasciolosis. Vet. Parasitol, 105, 337-343

Bont, J.D. (1995). Cattle schistosomosis: Host parasite interactions. PhD Thesis, Universisteit, Gent. Pp. 23.

Bushara, H.O., Majid, A.A., Saad, A.M., Hussein, M.F., Taylor, M.G., Dargie, J.D., Marshall, T.F de C. and Nelson, G.S. (1980). Observations on cattle schistosomiasis in the Sudan, a study in comparative medicine. II. Experimental demonstration of naturally acquired resistance to Schistosoma bovis. America Journal of Tropical Medicine Hygiene. 29, 442.

CSA (Central Statistical Agency),2008. Ethiopian Agricultural Sample Survey, 2007/08, Vol. II, Statistical report on Livestock and Livestock Characteristics, Addis Ababa, Ethiopia.

Dargie, J.D. (1980). The pathogenesis of Schistosoma bovis infection in Sudanese cattle. T. Roy. Soc. Trop. Med. H. 74, 560-562.

Fekade, D., Woldemichael, T.A. and Tadele, S. (1989). Pathogenesis and pathology of scistosomiasis, $5^{\text {th }}$ edition. Addis Ababa University Printing Press, Addis Ababa. Pp. 34.

Fraser, C.M., Bergeron, J.A., Maya, A. and Susan, E.A. (1991). The Merck veterinary manual: A handbook of diagnosis, therapy, and disease prevention and control for the veterinarian, $7^{\text {th }}$ edition U.S.A, Merck and Co., Inc. Pp 76-78.

Hailu, M. (1999). Observations on the prevalence and intensity of Schistosoma bovis infection in Bahir Dar area, north central Ethiopia. DVM Thesis, Faculty of Veterinary Medicine, Addis Ababa University

Lawerence, J.A. (1971). Bovine schistosomiasis in southern Africa. Helminthological Abstracts, 47, 261-270.

McCauley, E.H., Majid, A.A. and Tayed, A. (1984). Economic evaluation of the production impact of bovine schistosomosis and vaccination in the Sudan. Prev. Vet. Med., 2, 735-754. 
McCauley, E.H., Tayed, A. and Majid, A.A. (1983). Owner survey of schistosomosis mortality in Sudanese cattle. Trop. Anim. Hlth. and Prod., 15, 277-233.

Solomon, H. (1985). Schistosomosis in domestic ruminants in Bahir Dar, Ethiopia. DVM Thesis, Faculty of Veterinary Medicine, Addis Ababa University.

Soulsby, E.J.L (1982). Helminths, Arthropods and Protozoa of Domesticated Animlas. $7^{\text {th }}$ edition. Baillier Tindall. Pp78.

SPSS (Statistical Packages for the Social Science), 2002.version 11.5 SPSS Inc. 19892002, USA.

Thrusfield, M (1995). Veterinary epidemiology. $2^{\text {nd }}$ edition. UK, Blackwell Science. Pp. 182-189.

Urquhart, G..M., Armour, J., Duncan, J.L. and Jenning, F.W. (1997). Veterinary helminthology Veterinary Parasitology. New York Churchill Livingstone Inc. Pp. 114-116.

Williamson, G. and Payne W.J.A. (1959). A introduction to animal husbandry in the tropics. Longman, London, UK. Pp 447.

Yalelet, W. (2004). Survey on Bovine schistosomiasis in and around Bahir-Dar, Northwestern Ethiopia. DVM Thesis, Faculty of Veterinary Medicine, Addis Ababa University. 